\title{
Pengaruh Ketidakseimbangan Beban Terhadap Arus Netral dan Losses pada Trafo Distribusi
}

\author{
Julius Sentosa Setiadji ${ }^{1}$, Tabrani Machmudsyah ${ }^{2}$, Yanuar Isnanto ${ }^{1}$ \\ ${ }^{1}$ Fakultas Teknologi Industri, Jurusan Teknik Elektro, Universitas Kristen Petra \\ Jl. Siwalankerto 121-131, Surabaya \\ ${ }^{2}$ PT. PLN(Persero) Distribusi Jawa Timur \\ Email:julius@petra.ac.id
}

\begin{abstract}
ABSTRAK
Ketidakseimbangan beban pada suatu sistem distribusi tenaga listrik selalu terjadi dan penyebab ketidakseimbangan tersebut adalah pada beban-beban satu fasa pada pelanggan jaringan tegangan rendah. Akibat ketidakseimbangan beban tersebut muncullah arus di netral trafo. Arus yang mengalir di netral trafo ini menyebabkan terjadinya losses (rugi-rugi), yaitu losses akibat adanya arus netral pada penghantar netral trafo dan losses akibat arus netral yang mengalir ke tanah. Setelah dianalisa, diperoleh bahwa bila terjadi ketidakseimbangan beban yang besar $(28,67 \%)$, maka arus netral yang muncul juga besar $(118,6 \mathrm{~A})$, dan losses akibat arus netral yang mengalir ke tanah semakin besar pula $(8.62 \%)$.
\end{abstract}

Kata kunci: ketidakseimbangan beban, arus netral, losses.

\section{ABSTRACT}

The unbalanced load in electric power distribution system always happen and it is caused by single phase loads on low voltage system. The effect of the unbalanced load is appear as a neutral current. These neutral current cause losses, those are losses caused by neutral current in neutral conductor on distribution transformers and losses caused by neutral current flows to ground. In conclusion, when high unbalanced load happened $(28,67 \%)$, then the neutral current that appear is also high (118,6 A), ultimately the losses that caused by the neutral current flows to ground will be high too (8,62\%).

Keywords: unbalanced load, neutral current, losses.

\section{PENDAHULUAN}

Dewasa ini Indonesia sedang melaksanakan pembangunan di segala bidang. Seiring dengan laju pertumbuhan pembangunan maka dituntut adanya sarana dan prasarana yang mendukungnya seperti tersedianya tenaga listrik. Saat ini tenaga listrik merupakan kebutuhan yang utama, baik untuk kehidupan sehari-hari maupun untuk kebutuhan industri. Hal ini disebabkan karena tenaga listrik mudah untuk ditransportasikan dan dikonversikan ke dalam bentuk tenaga yang lain. Penyediaan tenaga listrik yang stabil dan kontinyu merupakan syarat mutlak yang harus dipenuhi dalam memenuhi kebutuhan tenaga listrik.

Dalam memenuhi kebutuhan tenaga listrik tersebut, terjadi pembagian beban-beban yang pada awalnya merata tetapi karena ketidakserempakan waktu penyalaan beban-beban tersebut maka menimbulkan ketidakseimbangan beban yang berdampak pada penyediaan tenaga listrik. Ketidakseimbangan beban antara tiap-tiap fasa (fasa $\mathrm{R}$, fasa $\mathrm{S}$, dan fasa $\mathrm{T}$ ) inilah yang menyebabkan mengalirnya arus di netral trafo.

Catatan: Diskusi untuk makalah ini diterima sebelum tanggal 1 Desember 2007. Diskusi yang layak muat akan diterbitkan pada Jurnal Teknik Elektro volume 8, nomor 1, Maret 2008.

\section{TEORI TRANSFORMATOR}

Transformator merupakan suatu alat listrik yang mengubah tegangan arus bolak-balik dari satu tingkat ke tingkat yang lain melalui suatu gandengan magnet dan berdasarkan prinsip-prinsip induksi-elektromagnet. Transformator terdiri atas sebuah inti, yang terbuat dari besi berlapis dan dua buah kumparan, yaitu kumparan primer dan kumparan sekunder.

Penggunaan transformator yang sederhana dan handal memungkinkan dipilihnya tegangan yang sesuai dan ekonomis untuk tiap-tiap keperluan serta merupakan salah satu sebab penting bahwa arus bolak-balik sangat banyak dipergunakan untuk pembangkitan dan penyaluran tenaga listrik.

Prinsip kerja transformator adalah berdasarkan hukum Ampere dan hukum Faraday, yaitu: arus listrik dapat menimbulkan medan magnet dan sebaliknya medan magnet dapat menimbulkan arus listrik. Jika pada salah satu kumparan pada transformator diberi arus bolak-balik maka jumlah garis gaya magnet berubah-ubah. Akibatnya pada sisi primer terjadi induksi. Sisi sekunder menerima garis gaya magnet dari sisi primer yang jumlahnya berubah-ubah pula. Maka di sisi sekunder juga timbul induksi, akibatnya antara dua ujung terdapat beda tegangan. 


\section{PERHITUNGAN ARUS BEBAN PENUH TRANSFORMATOR}

Daya transformator bila ditinjau dari sisi tegangan tinggi (primer) dapat dirumuskan sebagai berikut:

$$
\mathrm{S}=\sqrt{ } 3 . \mathrm{V} . \mathrm{I}
$$

dimana:

$\mathrm{S}=$ daya transformator $(\mathrm{kVA})$

$\mathrm{V}=$ tegangan sisi primer transformator $(\mathrm{kV})$

$\mathrm{I}=$ arus jala-jala $(\mathrm{A})$

Sehingga untuk menghitung arus beban penuh (full load) dapat menggunakan rumus :

$$
\mathrm{I}_{\mathrm{FL}}=\frac{\mathrm{S}}{\sqrt{3} \cdot \mathrm{V}}
$$

dimana:

$\mathrm{I}_{\mathrm{FL}}=$ arus beban penuh $(\mathrm{A})$

$\mathrm{S}=$ daya transformator $(\mathrm{kVA})$

$\mathrm{V}=$ tegangan sisi sekunder transformator $(\mathrm{kV})$

\section{Losses (rugi-rugi) Akibat Adanya Arus Netral pada Penghantar Netral Transformator.}

Sebagai akibat dari ketidakseimbangan beban antara tiap-tiap fasa pada sisi sekunder trafo (fasa $\mathrm{R}$, fasa $\mathrm{S}$, fasa T) mengalirlah arus di netral trafo. Arus yang mengalir pada penghantar netral trafo ini menyebabkan losses (rugi-rugi). Losses pada penghantar netral trafo ini dapat dirumuskan sebagai berikut:

$$
\mathrm{P}_{\mathrm{N}}=\mathrm{I}_{\mathrm{N}}^{2} \cdot \mathrm{R}_{\mathrm{N}}
$$

dimana:

$\mathrm{P}_{\mathrm{N}}=$ losses pada penghantar netral trafo (watt)

$\mathrm{I}_{\mathrm{N}}=$ arus yang mengalir pada netral trafo $(\mathrm{A})$

$\mathrm{R}_{\mathrm{N}}=$ tahanan penghantar netral trafo $(\Omega)$

Sedangkan losses yang diakibatkan karena arus netral yang mengalir ke tanah (ground) dapat dihitung dengan perumusan sebagai berikut :

$$
\mathrm{P}_{\mathrm{G}}=\mathrm{I}_{\mathrm{G}}^{2} \cdot \mathrm{R}_{\mathrm{G}}
$$

dimana:

$\mathrm{P}_{\mathrm{G}}=$ losses akibat arus netral yang mengalir ke tanah (watt)

$\mathrm{I}_{\mathrm{G}}=$ arus netral yang mengalir ke tanah $(\mathrm{A})$

$\mathrm{R}_{\mathrm{G}}=$ tahanan pembumian netral trafo $(\Omega)$

\section{Ketidakseimbangan Beban}

Yang dimaksud dengan keadaan seimbang adalah suatu keadaan di mana :

- Ketiga vektor arus / tegangan sama besar.

- Ketiga vektor saling membentuk sudut $120^{\circ}$ satu sama lain.

Sedangkan yang dimaksud dengan keadaan tidak seimbang adalah keadaan di mana salah satu atau kedua syarat keadaan seimbang tidak terpenuhi. Kemungkinan keadaan tidak seimbang ada 3 yaitu:

- Ketiga vektor sama besar tetapi tidak membentuk sudut $120^{\circ}$ satu sama lain.

- Ketiga vektor tidak sama besar tetapi membentuk sudut $120^{\circ}$ satu sama lain.

- Ketiga vektor tidak sama besar dan tidak membentuk sudut $120^{\circ}$ satu sama lain.

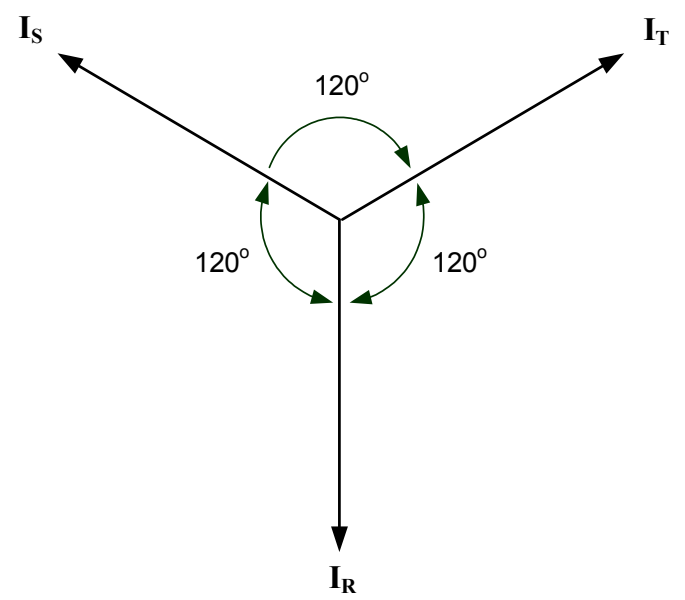

(a)

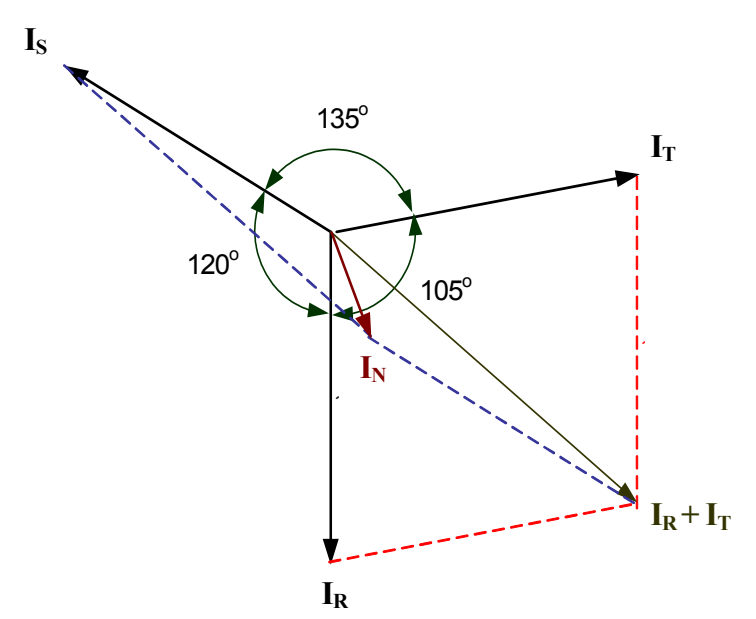

(b)

Gambar 1. Vektor Diagram Arus

Gambar 1(a) menunjukkan vektor diagram arus dalam keadaan seimbang. Di sini terlihat bahwa penjumlahan ketiga vektor arusnya $\left(\mathrm{I}_{\mathrm{R}}, \mathrm{I}_{\mathrm{S}}, \mathrm{I}_{\mathrm{T}}\right)$ adalah sama dengan nol sehingga tidak muncul arus netral $\left(\mathrm{I}_{\mathrm{N}}\right)$. Sedangkan pada Gambar 1(b) menunjukkan vektor diagram arus yang tidak seimbang. Di sini terlihat bahwa penjumlahan ketiga vektor arusnya $\left(I_{R}\right.$, $\mathrm{I}_{\mathrm{S}}, \mathrm{I}_{\mathrm{T}}$ ) tidak sama dengan nol sehingga muncul sebuah besaran yaitu arus netral $\left(\mathrm{I}_{\mathrm{N}}\right)$ yang besarnya bergantung dari seberapa besar faktor ketidakseimbangannya. 


\section{Penyaluran dan Susut Daya}

Misalnya daya sebesar P disalurkan melalui suatu saluran dengan penghantar netral. Apabila pada penyaluran daya ini arus-arus fasa dalam keadaan seimbang, maka besarnya daya dapat dinyatakan sebagai berikut:

$$
\mathrm{P}=3 \cdot[\mathrm{V}] \cdot[\mathrm{I}] \cdot \cos \varphi
$$

dengan:

$\mathrm{P} \quad=$ daya pada ujung kirim

$\mathrm{V} \quad=$ tegangan pada ujung kirim

$\cos \varphi=$ faktor daya

Daya yang sampai ujung terima akan lebih kecil dari $\mathrm{P}$ karena terjadi penyusutan dalam saluran.

Jika [I] adalah besaran arus fasa dalam penyaluran daya sebesar P pada keadaan seimbang, maka pada penyaluran daya yang sama tetapi dengan keadaan tak seimbang besarnya arus-arus fasa dapat dinyatakan dengan koefisien $\mathrm{a}, \mathrm{b}$ dan $\mathrm{c}$ sebagai berikut :

$$
\begin{aligned}
& {\left[I_{R}\right]=a[I]} \\
& {\left[I_{S}\right]=b[I]} \\
& {\left[I_{T}\right]=c[I]}
\end{aligned}
$$

dengan $\mathrm{I}_{R}, \mathrm{I}_{\mathrm{S}}$ dan $\mathrm{I}_{\mathrm{T}}$ berturut-turut adalah arus di fasa $\mathrm{R}, \mathrm{S}$ dan T.

Bila faktor daya di ketiga fasa dianggap sama walaupun besarnya arus berbeda, besarnya daya yang disalurkan dapat dinyatakan sebagai :

$$
\mathrm{P}=(\mathrm{a}+\mathrm{b}+\mathrm{c}) \cdot[\mathrm{V}] \cdot[\mathrm{I}] \cdot \cos \varphi
$$

Apabila persamaan (7) dan persamaan (5) menyatakan daya yang besarnya sama, maka dari kedua persamaan itu dapat diperoleh persyaratan untuk koefisien a, b, dan c yaitu :

$$
a+b+c=3
$$

dimana pada keadaan seimbang, nilai $\mathrm{a}=\mathrm{b}=\mathrm{c}=1$

\section{Pengumpulan Data:}

Spesifikasi Trafo Tiang adalah sebagai berikut:

$\begin{array}{lll}\text { Buatan Pabrik } & : & \text { TRAFINDO } \\ \text { Tipe } & : \text { Outdoor } \\ \text { Daya } & : & 200 \mathrm{kVA} \\ \text { Tegangan Kerja } & : & 21 / 20,5 / 20 / 19,5 / 19 \mathrm{kV} / / 400 \mathrm{~V} \\ \text { Arus } & : & 6,8-359 \mathrm{~A} \\ \text { Hubungan } & : & \text { Dyn5 } \\ \text { Impedansi } & : 4 \% \\ \text { Trafo } & : 1 \times 3 \text { phasa }\end{array}$

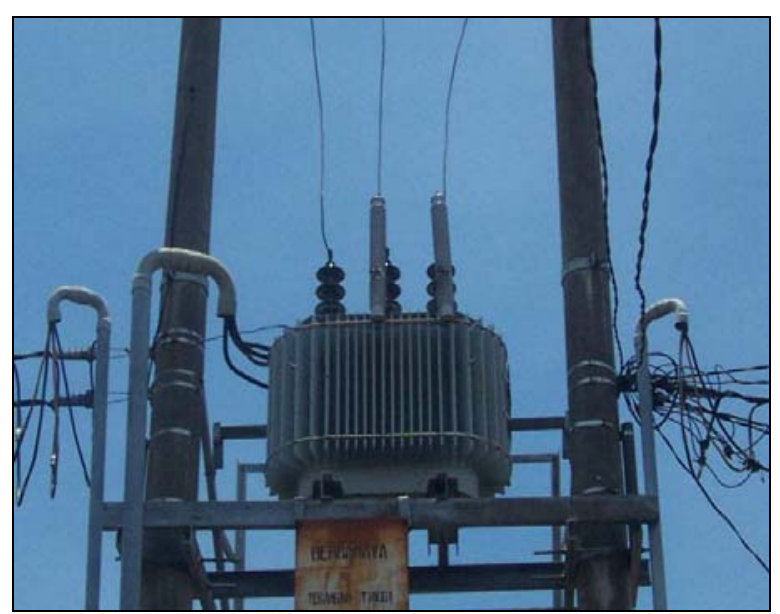

Gambar 2. Trafo Distribusi 200 kVA

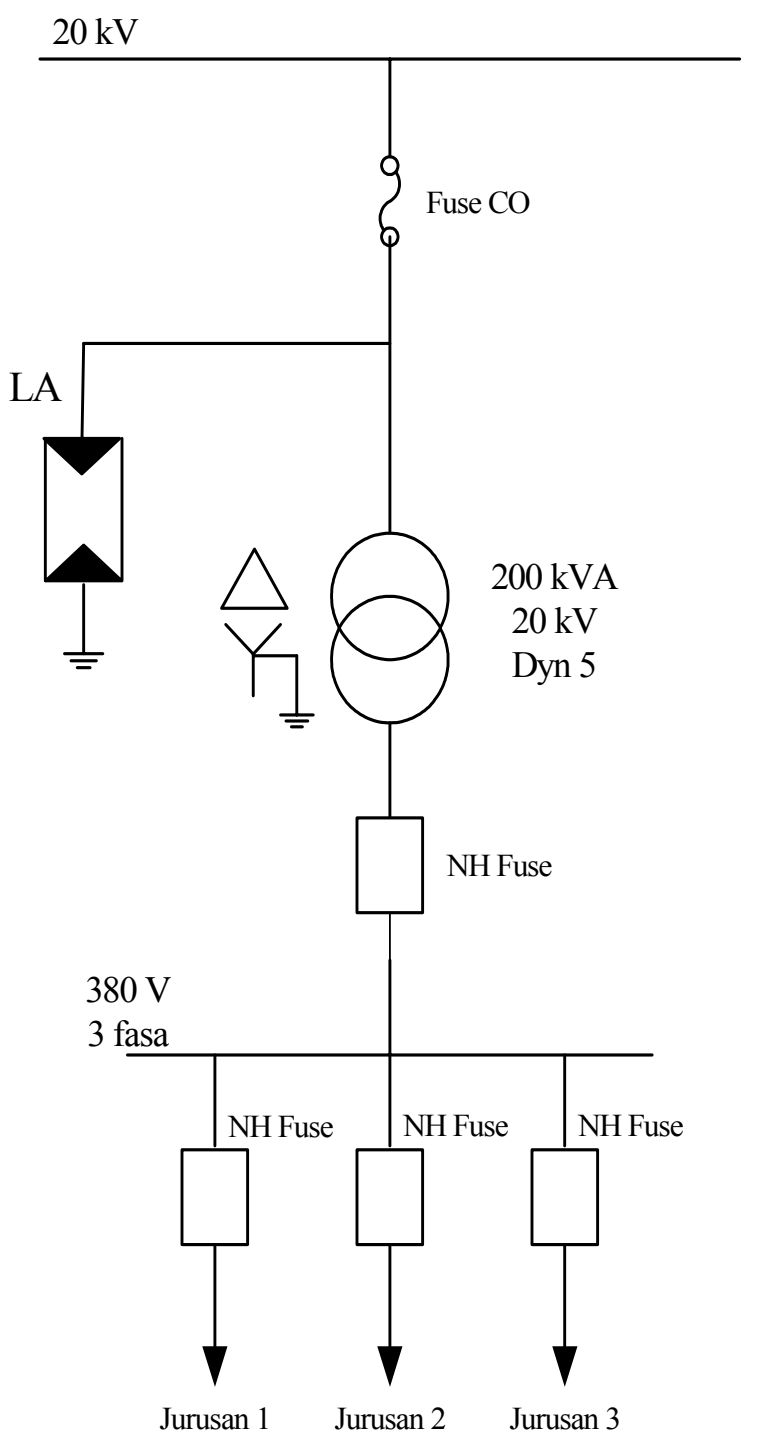

Gambar 3. Single Line Trafo Distribusi 200 kVA 
Tabel 1. Hasil Pengukuran Trafo Distribusi 200 kVA

\begin{tabular}{|c|c|c|c|c|}
\hline Fasa & $\begin{array}{c}\mathrm{S} \\
(\mathrm{kVA})\end{array}$ & $\begin{array}{l}\text { Vp-n } \\
\text { (V) }\end{array}$ & $\begin{array}{c}\text { I } \\
\text { (A) }\end{array}$ & $\operatorname{Cos} \varphi$ \\
\hline \multicolumn{5}{|c|}{ Pengukuran pada siang hari } \\
\hline $\mathrm{R}$ & 50,42 & 226 & 223,1 & 0,95 \\
\hline S & 37,34 & 226 & 165,0 & 0,94 \\
\hline $\mathrm{T}$ & 20,56 & 227 & 90,6 & 0,95 \\
\hline $\mathrm{I}_{\mathrm{N}}$ & \multicolumn{4}{|c|}{$118,6 \mathrm{~A}$} \\
\hline $\mathrm{I}_{\mathrm{G}}$ & \multicolumn{4}{|c|}{$62,1 \mathrm{~A}$} \\
\hline $\mathrm{R}_{\mathrm{G}}$ & \multicolumn{4}{|c|}{$3,8 \Omega$} \\
\hline \multicolumn{5}{|c|}{ Pengukuran pada malam hari } \\
\hline $\mathrm{R}$ & 68,22 & 225 & 303,6 & 0,91 \\
\hline $\mathrm{S}$ & 42,42 & 226 & 187,7 & 0,92 \\
\hline $\mathrm{T}$ & 37,38 & 226 & 165,4 & 0,94 \\
\hline $\mathrm{I}_{\mathrm{N}}$ & \multicolumn{4}{|c|}{$131,7 \mathrm{~A}$} \\
\hline $\mathrm{I}_{\mathrm{G}}$ & \multicolumn{4}{|c|}{$58,9 \mathrm{~A}$} \\
\hline $\mathrm{R}_{\mathrm{G}}$ & \multicolumn{4}{|c|}{$3,8 \Omega$} \\
\hline
\end{tabular}

Ukuran kawat untuk penghantar netral trafo adalah 50 $\mathrm{mm}^{2}$ dengan $\mathrm{R}=0,6842 \Omega / \mathrm{km}$, sedangkan untuk kawat penghantar fasanya adalah $70 \mathrm{~mm}^{2}$ dengan $\mathrm{R}=$ $0,5049 \Omega / \mathrm{km}$.

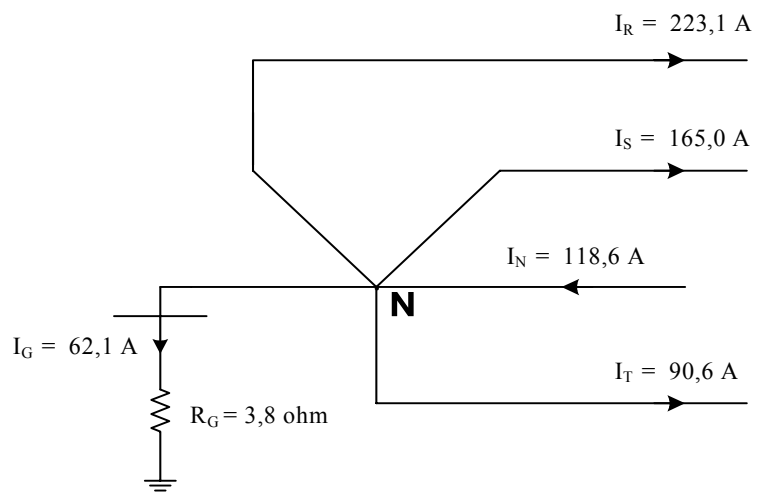

Gambar 4. Skema Aliran Arus di Sisi Sekunder Trafo pada Siang Hari.

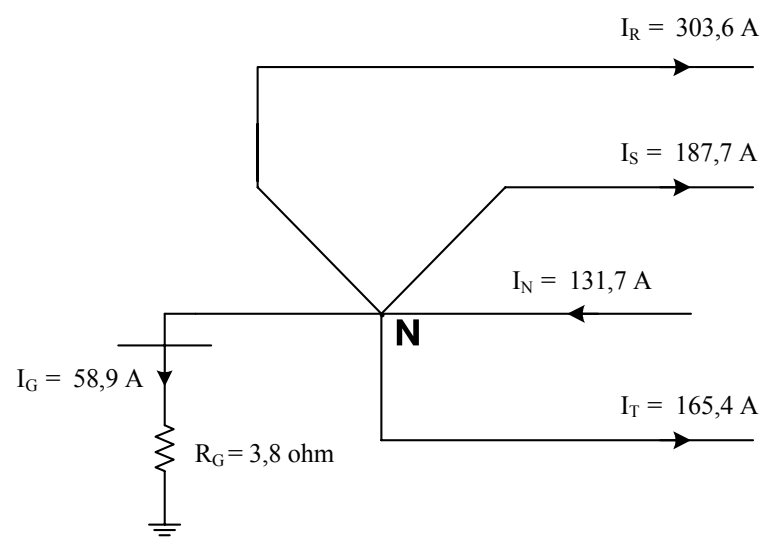

Gambar 5. Skema Aliran Arus di Sisi Sekunder Trafo pada Malam Hari.

\section{Analisa Pembebanan Trafo}

$\mathrm{S}=200 \mathrm{kVA}$

$\mathrm{V}=0,4 \mathrm{kV}$ phasa - phasa

$\mathrm{I}_{\mathrm{FL}}=\frac{S}{\sqrt{3} \times V}=\frac{200000}{\sqrt{3} \times 400}=288,68$ Ampere

$$
\begin{aligned}
\mathrm{I}_{\text {rata siang }} & =\frac{I_{R}+I_{S}+I_{T}}{3}=\frac{223,1+165,0+90,6}{3} \\
& =159,67 \text { Ampere }
\end{aligned}
$$

$$
\begin{aligned}
\mathrm{I}_{\text {rata malam }} & =\frac{I_{R}+I_{S}+I_{T}}{3}=\frac{303,6+187,7+165,4}{3} \\
& =218,90 \text { Ampere }
\end{aligned}
$$

Persentase pembebanan trafo adalah:

- Pada siang hari:

$$
\frac{I_{\text {ratasiang }}}{I_{F L}}=\frac{159.67}{288.68}=55.31 \%
$$

- Pada malam hari:

$$
\frac{I_{\text {ratamalam }}}{I_{F L}}=\frac{218.90}{288.68}=75.83 \%
$$

Dari perhitungan di atas terlihat bahwa pada saat malam hari (WBP $=$ Waktu Beban Puncak) persentase pembebanan cukup tinggi yaitu $75.83 \%$.

Analisa Ketidakseimbangan Beban pada Trafo

- Pada Siang Hari :

Dengan menggunakan persamaan (6), koefisien a, $\mathrm{b}$, dan $\mathrm{c}$ dapat diketahui besarnya, dimana besarnya arus fasa dalam keadaan seimbang ( I ) sama dengan besarnya arus rata-rata ( Irata ).

$\mathrm{I}_{\mathrm{R}}=\mathrm{a} . \mathrm{I}$ maka $: \mathrm{a}=\frac{\mathrm{I}_{\mathrm{R}}}{\mathrm{I}}=\frac{223,1}{159,67}=1,40$

$\mathrm{I}_{\mathrm{S}}=\mathrm{b} . \mathrm{I}$ maka $: \mathrm{b}=\frac{\mathrm{I}_{\mathrm{S}}}{\mathrm{I}}=\frac{165,0}{159,67}=1,03$

$\mathrm{I}_{\mathrm{T}}=\mathrm{c} . \mathrm{I}$ maka $: \mathrm{c}=\frac{\mathrm{I}_{\mathrm{T}}}{\mathrm{I}}=\frac{90,6}{159,67}=0,57$

Pada keadaan seimbang, besarnya koefisien $a, b$ dan $\mathrm{c}$ adalah 1 .

Dengan demikian, rata-rata ketidakseimbangan beban (dalam \%) adalah:

$$
\begin{aligned}
& =\frac{\{|\mathrm{a}-1|+|\mathrm{b}-1|+|\mathrm{c}-1|\}}{3} \times 100 \% \\
& =\frac{\{|1,40-1|+|1,03-1|+|0,57-1|\}}{3} \times 100 \%=28,67 \%
\end{aligned}
$$


- Pada Malam Hari :

Dengan menggunakan persamaan (6), koefisien a, $\mathrm{b}$, dan $\mathrm{c}$ dapat diketahui besarnya, dimana besarnya arus fasa dalam keadaan seimbang ( I ) sama dengan besarnya arus rata-rata $\left(\mathrm{I}_{\text {rata }}\right)$.

$I_{R}=a \cdot I \quad$ maka $: a=\frac{I_{R}}{I}=\frac{303,6}{218,9}=1,39$

$\mathrm{I}_{\mathrm{S}}=\mathrm{b} . \mathrm{I} \quad$ maka $: \mathrm{b}=\frac{\mathrm{I}_{\mathrm{S}}}{\mathrm{I}}=\frac{187,7}{218,9}=0,86$

$\mathrm{I}_{\mathrm{T}}=\mathrm{c} . \mathrm{I} \quad$ maka $: \quad \mathrm{c}=\frac{\mathrm{I}_{\mathrm{T}}}{\mathrm{I}}=\frac{165,4}{218,9}=0,75$

Pada keadaan seimbang, besarnya koefisien $a, b$ dan c adalah 1 .

Dengan demikian, rata-rata ketidakseimbangan beban (dalam \%) adalah:

$$
=\frac{\{|1,39-1|+|0,86-1|+|0,75-1|\}}{3} \times 100 \%=26.00 \%
$$

Dari perhitungan di atas terlihat bahwa baik pada siang hari maupun malam hari, ketidakseimbangan beban cukup tinggi (> 25\%), hal ini disebabkan karena penggunaan beban yang tidak merata di antara konsumen.

\section{Analisa Losses Akibat Adanya Arus Netral pada Penghantar Netral Trafo dan Losses Akibat Arus Netral yang Mengalir ke Tanah}

- Pada Siang Hari:

Dari tabel pengukuran, dan dengan menggunakan persamaan (3), losses akibat adanya arus netral pada penghantar netral trafo dapat dihitung besarnya, yaitu:

$$
\begin{aligned}
\mathrm{P}_{\mathrm{N}} & =\mathrm{I}_{\mathrm{N}}^{2} \cdot \mathrm{R}_{\mathrm{N}}=(118,6)^{2} \cdot 0,6842 \\
& =9623,92 \text { Watt } \approx 9,62 \mathrm{~kW}
\end{aligned}
$$

dimana daya aktif trafo $(\mathrm{P})$ :

$\mathrm{P}=\mathrm{S} \cdot \cos \varphi$, dimana $\cos \varphi$ yang digunakan adalah 0,85

$\mathrm{P}=200.0,85=170 \mathrm{~kW}$

Sehingga, persentase losses akibat adanya arus netral pada penghantar netral trafo adalah:

$$
\begin{aligned}
\% \mathrm{P}_{\mathrm{N}} & =\frac{\mathrm{P}_{\mathrm{N}}}{\mathrm{P}} \times 100 \%=\frac{9,62 \mathrm{~kW}}{170 \mathrm{~kW}} \times 100 \% \\
& =5.66 \%
\end{aligned}
$$

Losses akibat arus netral yang mengalir ke tanah dapat dihitung besarnya dengan menggunakan persamaan (4), yaitu:

$$
\begin{aligned}
\mathrm{P}_{\mathrm{G}} & =\mathrm{I}_{\mathrm{G}}^{2} \cdot \mathrm{R}_{\mathrm{G}}=(62,1)^{2} \cdot 3,8=14654,4 \text { Watt } \\
& \approx 14,65 \mathrm{~kW}
\end{aligned}
$$

Dengan demikian persentase losses-nya adalah:

$$
\begin{aligned}
\% \mathrm{P}_{\mathrm{G}} & =\frac{\mathrm{P}_{\mathrm{G}}}{\mathrm{P}} \times 100 \%=\frac{14,65 \mathrm{~kW}}{170 \mathrm{~kW}} \times 100 \% \\
& =8,62 \%
\end{aligned}
$$

- Pada Malam Hari:

Dari tabel pengukuran, dan dengan menggunakan persamaan (3), losses akibat adanya arus netral pada penghantar netral trafo dapat dihitung besarnya, yaitu:

$$
\begin{aligned}
\mathrm{P}_{\mathrm{N}} & =(131,7)^{2} \cdot 0,6842=11867.37 \text { Watt } \\
& \approx 11,87 \mathrm{~kW}
\end{aligned}
$$

Sehingga, persentase losses akibat adanya arus netral pada penghantar netral trafo adalah :

$\% \mathrm{P}_{\mathrm{N}}=\frac{11.87 \mathrm{~kW}}{170 \mathrm{~kW}} \times 100 \%=6,98 \%$

Losses akibat arus netral yang mengalir ke tanah dapat dihitung besarnya dengan menggunakan persamaan (4), yaitu:

$\mathrm{P}_{\mathrm{G}}=(58,9)^{2} \cdot 3,8=13183,00$ Watt $\approx 13,18 \mathrm{~kW}$

Dengan demikian persentase losses akibat arus netral yang mengalir ke tanah adalah:

$$
\% \mathrm{P}_{\mathrm{G}}=\frac{13,18 \mathrm{~kW}}{170 \mathrm{~kW}} \times 100 \%=7,75 \%
$$

Tabel 2. Losses pada Trafo Distribusi 200 kVA

\begin{tabular}{ccccccccc}
\hline $\begin{array}{c}\mathbf{R}_{\mathbf{N}} \\
(\Omega)\end{array}$ & Waktu & $\begin{array}{c}\text { Ketidak- } \\
\text { seimbangan } \\
\text { Beban(\%) }\end{array}$ & $\begin{array}{c}\mathbf{I}_{\mathbf{N}} \\
(\mathbf{A})\end{array}$ & $\begin{array}{c}\mathbf{I}_{\mathbf{G}} \\
(\mathbf{A})\end{array}$ & $\begin{array}{c}\mathbf{P}_{\mathbf{N}} \\
(\mathbf{k W})\end{array}$ & $\begin{array}{c}\mathbf{P}_{\mathbf{N}} \\
(\mathbf{\%})\end{array}$ & $\begin{array}{c}\mathbf{P}_{\mathbf{G}} \\
(\mathbf{k W})\end{array}$ & $\begin{array}{c}\mathbf{P}_{\mathbf{G}} \\
(\mathbf{\%})\end{array}$ \\
\hline $\begin{array}{c}0,6842 \\
\left(50 \mathrm{~mm}^{2}\right)\end{array}$ & Siang & 28,67 & 118,6 & 62,1 & 9,62 & 5,66 & 14,65 & 8,62 \\
\hline $\begin{array}{c}0,5049 \\
\left(70 \mathrm{~mm}^{2}\right)\end{array}$ & Malam & 26,00 & 131,7 & 58,9 & 11,87 & 6,98 & 13,18 & 7,75 \\
\cline { 2 - 10 } & Malam & 28,67 & 118,6 & 62,1 & 7.10 & 4.18 & 14,65 & 8,62 \\
\hline
\end{tabular}

Pada Tabel 2 terlihat bahwa semakin besar arus netral yang mengalir di penghantar netral trafo $\left(\mathrm{I}_{\mathrm{N}}\right)$ maka semakin besar losses pada penghantar netral trafo $\left(\mathrm{P}_{\mathrm{N}}\right)$. Demikian pula bila semakin besar arus netral yang mengalir ke tanah $\left(\mathrm{I}_{\mathrm{G}}\right)$, maka semakin besar losses akibat arus netral yang mengalir ke $\tan a h\left(\mathrm{P}_{\mathrm{G}}\right)$.

Dengan semakin besar arus netral dan losses di trafo maka effisiensi trafo menjadi turun. Bila ukuran kawat penghantar netral dibuat sama dengan kawat penghantar fasanya $\left(70 \mathrm{~mm}^{2}\right)$ maka losses arus netralnya akan turun.

\section{KESIMPULAN}

Berdasarkan analisa data di atas, terlihat bahwa pada siang hari ketidakseimbangan beban pada trafo tiang semakin besar karena penggunaan beban listrik tidak merata.

Sesuai Tabel 2, semakin besar ketidakseimbangan beban pada trafo tiang maka arus netral yang 
mengalir ke tanah $\left(\mathrm{I}_{\mathrm{G}}\right)$ dan losses trafo tiang semakin besar.

Salah satu cara mengatasi losses arus netral adalah dengan membuat sama ukuran kawat netral dan fasa.

\section{DAFTAR PUSTAKA}

[1] Abdul Kadir, Distribusi dan Utilisasi Tenaga Listrik, Jakarta: UI - Press, 2000.

[2] Persyaratan Umum Instalasi Listrik 2000 (PUIL 2000), Jakarta: Badan Standarisasi Nasional, 2000 .
[3] James J.Burke, Power Distribution EngineeringFundamentals And Applications, New York: Marcel Dekker Inc., 1994.

[4] Sudaryatno Sudirham, Dr., Pengaruh Ketidakseimbangan Arus Terhadap Susut Daya pada Saluran, Bandung: ITB, Tim Pelaksana Kerjasama PLN-ITB, 1991.

[5] Sulasno, Ir., Teknik Tenaga Listrik, Semarang : Satya Wacana, 1991.

[6] Zuhal, Dasar Tenaga Listrik, Bandung: ITB, 1991.

[7] Abdul Kadir, Transformator, Jakarta: PT. Elex Media Komputindo, 1989. 